\title{
PENGARUH MENGUNYAH BUAH APEL DAN JAMBU BIJI MERAH TERHADAP DEBRIS INDEKS
}

\author{
Siti Hidayati ${ }^{\bowtie 1}$, Dwi Suyatmi ${ }^{2}$
}

\begin{abstract}
ABSTRAK
Debris adalah sisa makanan yang terdapat dalam rongga mulut, apabila tidak segera dibersihkan akan menyebabkan penyakit karies gigi. Debris bisa dibersihkan secara mekanis maupun kimiawi. Salah satu cara untuk membersihkan debris adalah dengan mengunyah buah apel dan jambu biji merah, tekstur buahnya yang berserat dan berair dapat membersihkan gigi secara alami. Tujuan penelitian ini untuk mengetahui pengaruh mengunyah buah apel dan jambu biji merah terhadap debris indeks.

Metode penelitian ini adalah eksperimen semu dengan pendekatan pre dan post test. Populasi dan sampel penelitian adalah siswa usia 8-10 tahun. Sampel merupakan 40 siswa yang dibagi menjadi 2 kelompok: 20 siswa masuk kelompok perlakuan mengunyah buah apel dan 20 siswa kelompok perlakuan mengunyah jambu biji merah. Pengambilan sampel dengan menggunakan teknik total sampling. Variabel Pengaruh adalah mengunyah buah apel dan jambu biji merah, Variabel terpengaruh adalah debris indeks.

Uji paired T Test menunjukkan hasil $P=0,000$, berarti $p<0,05$, sedangkan uji Independent T Test menunjukkan hasil $P=0,001$, berarti $p$ Value $<0.05$. Kesimpulan penelitian adalah mengunyah buah apel dan jambu biji merah berpengaruh terhadap debris indeks. Mengunyah buah apel lebih efektif dari pada mengunyah jambu biji merah dalam menurunkan debris indeks.
\end{abstract}

Kata kunci : Buah apel, jambu biji merah, debris indeks

\begin{abstract}
Debris is food accumulation contained in the oral cavity, if not promptly cleaned will cause dental caries disease. Debris can be cleaned mechanically or chemically. One of the way to clean debris by chewing apples and guava, fibrous texture and juicy fruit, so it can clean teeth naturally. The purpose of this study was to determine the effect of chewing an apple and red guava against debris index.

This research method is quasy experimental with pre and post test design. Population were students aged 8-10 years. Samples are 40 students who were divided into 2 groups: 20 students as treatment group chewing apples and 20 students chewing guava as control group. Sampling using total sampling techniques. Independent variables was munching apples and guava red while dependent variable was debris index,

Results: from paired $T$ test showed the results of $p=0.000$, mean $p<0.05$, while the independent $T$ test showed the results of $p=0,001$, meaning $p$ Value of <0.05. Conclusion: Chewing apples and guava red effect on the index debris. Chewing apples are more effective than chewing guava in decreasing debris index.
\end{abstract}

Key words : apple, guava red, debris index

$\overline{1,2}$ ) Dosen Jurusan Keperawatan Gigi Poltekkes Kemenkes Yogyakarta

$\otimes^{凶}$ jkg.hidayati@gmail.com 


\section{PENDAHULUAN}

Penyakit gigi dan mulut yang banyak di derita masyarakat Indonesia adalah gingivitis dan karies gigi, sumber dari kedua penyakit tersebut adalah akibat terabaikannya kebersihan gigi dan mulut, sehingga terjadilah akumulasi plak (Putri, 2012). Gigi yang berlubang tentu tidak sehat, masyarakat Indonesia masih belum mempertimbangkan kesehatan gigi dan mulut.Hal ini terlihat dari $50 \%$ orang Indonesia berusia di atas 10 tahun memiliki masalah karies gigi yang belum teratasi.Fakta yang lainnya menunujukkan bahwa seseorang yang menderita penyakit gigi dan mulut tersebut bersifat agresif kumulatif, artinya daerah yang rusak tersebut tidak dapat disembuhkan (Mangku, 2009).

Mulut merupakan bagian tubuh yang sangat penting, maka harus dijaga kebersihannya salah satunya dengan cara menyikat gigi secara teratur dan benar. Menyikat gigi yang dianjurkan adalah setiap sehabis makan dan sebelum tidur.Untuk menentukan kebersihan gigi dan mulut seseorang dapat diukur dengan menggunakan indeks. Indeks adalah suatu angka yang menunjukkan keadaan klinis yang didapat pada waktu melakukan pemeriksaan, dengan cara mengukur luas permukaan gigi yang tertutup oleh debris dan kalkulus. Debris adalah sisa makanan yang terdapat di dalam mulut (Sandira, 2009).

Konsumsi buah yang segar dan kaya akan vitamin, mineral, serat dan air dapat melancarkan pembersihan sendiri pada gigi, sehingga luas permukaan debris dapat dikurangi dan pada akhirnya karies gigi dapat dicegah (Hidayanti, 2007).

Upaya preventif pada anak diperlukan untuk mengatasi karies gigi, dilakukan secara sistematis dan sedini mungkin yaitu pada usia muda. Usia 8-10 tahun merupakan kelompok usia yang kritis terhadap terjadinya karies gigi dan mempunyai sifat khusus yaitu transisi pergantian gigi susu ke gigi permanen. Anak usia 8-10 tahun prevalensi karies gigi mencapai 60-85\%. Pemilihan murid Sekolah Dasar (SD) sebagai obyek Usaha Kesehatan Gigi Sekolah (UKGS) sangat penting mengingat kurangnya perhatian akan kesehatan gigi anak usia sekolah dasar dan pada dasarnya anak pada usia ini sangat peka terhadap pendidikan baik dari perilaku maupun pola kebiasaan dan dalam pertumbuhan masih dapat diperbaiki (Angela, 2005).

Mengunyah makanan berserat seperti buah-buahan dapat membantu membersihkan gigi, contohnya pepaya, nanas, semangka, apel, bengkoang, jambu biji merah adalah contoh dari buah-buahan yang mudah dijumpai dan dapat langsung dikonsumsi dalam keadaan segar (Cahyati, 2013).

Ada beberapa macam makanan berserat dan berair yang dapat diperoleh di pasaran seperti buah-buahan. Hal lain dari buah-buahan adalah kemampuannya untuk dapat melakukan self cleansing terhadap rongga mulut. Makanan padat dan juga berserat dari buah dan sayur secara fisiologis akan memaksa mulut manusia untuk menggerus dan menghancurkannya sebelum masuk ke saluran pencernaan selanjutnya, sehingga dapat mendorong sekresi air ludah (Milati, 2009).

Kandungan serat dan air dari apel dapat merangsang kecepatan sekresi saliva dan dapat menetralkan zat-zat asam. Apel juga mengandung tannin yang bersifat sebagai pengelat (astringent) yang bersifat spasmolitik dan sebagai antiseptic.Tannin juga membantu menghambat pertumbuhan bakteri dalam gigi sehingga menghambat pertumbuhan plak penyebab karies gigi dan penyakit pada gusi. Makan buah apel mempunyai efek membersihkan gigi dan mulut setelah makan yang dapat menghambat terbentuknya plak gigi, sehingga buah ini sering disebut buah yang memiliki daya membersihkan gigi atau self cleansing (Lestari, 2004).

Selain apel, buah jambu merah juga memiliki kandungan air dan serat yang tinggi. Jambu biji adalah salah satu tanaman jenis perdu, dalam bahasa Inggris disebut 
Lambo guava. Tanaman ini berasal dari Brazilia Amerika Tengah, menyebar ke Thailand kemudian ke Negara Asia lainnya seperti Indonesia. Hingga saat ini telah dibudidayakan dan menyebar luas di daerahdaerah jawa. Jambu biji sering disebut juga jambu kluthuk, jambu siki atau jambu batu. Jambu biji masih banyak orang menganggap remeh, padahal banyak manfaatnya bagi kesehatan dari zat kimia yang dikandungnya. Buah jambu biji besarnya cukup bervariasi, dari yang berdiameter $2,5 \mathrm{~cm}$ sampai $10 \mathrm{~cm}$ Jambu yang disukai oleh masyarakat umumnya adalah yang berdaging lunak dan tebal, rasanya manis, berbiji sedikit dan buahnya berukuran besar (Dalimuntho, 2008).

Tujuan dari penelitian ini mengetahui pengaruh mengunyah buah apel dan jambu biji merah terhadap debris indeks pada anak usia 8-10 tahun SD Muhammadiyah Sangonan II Sidoluhur Godean Sleman.

\section{METODE PENELITIAN}

Penelitian ini adalah penelitian eksperimen semu (quasi experiment) Adapun rancangan penelitian yang digunakan adalah two group pretest and posttest. Debris indeks diamati sebanyak dua kali yaitu sebelum perlakuan dan sesudah perlakuan.

Adapun rancangan penelitian adalah sebagai berikut :

\begin{tabular}{|l|l|l|l|l|l|}
\hline $\begin{array}{l}\text { Kelompok } \\
\text { Perlakuan 1 }\end{array}$ & $\mathrm{O}_{1}$ & - & $\mathrm{X}_{1}$ & & \\
\hline $\begin{array}{l}\text { Kelompok } \\
\text { Perlakuan 2 }\end{array}$ & $\mathrm{O}_{3}$ & & $\mathrm{O}_{2}$ \\
\hline
\end{tabular}

Keterangan :

$\mathrm{O}_{1}$ : Pengukuran debris indeks sebelum mengunyah buah apel

$\mathrm{X}_{1}$ : Perlakuan berupa mengunyah buah apel

$\mathrm{O}_{2}$ : Pengukuran debris indeks sesudah mengunyah buah apel

$\mathrm{O}_{3}$ : Peengukuran debris indeks sebelum mengunyah buah jambu biji merah

$\mathrm{X}_{2}$ : Perlakuan berupa mengunyah buah jambu biji merah

$\mathrm{O}_{4}$ : Pengukuran debris indeks sesudah mengunyah buah jambu biji merah
Pengambilan sampel secara Total Sampling sebanyak 40 anak usia 8 -10 tahun SD Muhammadiyah Sangonan II Sidoluhur Godean Sleman. Data hasil penelitian disajikan secara deskriptif kuantitatif yaitu mendeskripsikan hasil penelitian ke dalam tabel. Adapun untuk mengetahui pengaruh mengunyah buah apel dan jambu biji merah terhadap debris indeks dilakukan uji paired $t$ test. Efektifitas antara mengunyah buah apel dengan jambu biji merah terhadap perubahan debris indeks menggunakan Independent $t$ test.

\section{HASIL DAN PEMBAHASAN}

Penelitian dengan judul "Pengaruh Mengunyah Buah Apel dan Jambu Biji Merah Terhadap Debris Indeks" telah dilaksanakan dengan jumlah sampel 40 responden, yang dibagi menjadi 2 kelompok perlakuan yaitu kelompok 1 diberi perlakuan mengunyah buah apel dan kelompok 2 diberi perlakuan mengunyah jambu biji merah.

Tabel 1. Distribusi Frekuensi Debris Indeks Berdasarkan Usia Responden

\begin{tabular}{cccccccc}
\multicolumn{7}{c}{ Berdasarkan Usia Responden } \\
\hline Usia & \multirow{2}{*}{ Jumlah } & Baik & $\%$ & Sedang & $\%$ & Buruk & $\%$ \\
\hline 8 Tahun & 20 & 3 & & 9 & & 8 & \\
9 Tahun & 14 & 1 & & 6 & 7 & \\
10 Tahun & 6 & 0 & & 6 & & 0 & \\
& 40 & 4 & 10 & 21 & 52,5 & 15 & 37,5 \\
\hline
\end{tabular}

Tabel 1 menunjukkan bahwa debris indeks anak usia 8-10 tahun paling banyak berada pada kriteria sedang yaitu sejumlah 21 responden $(52,5 \%)$.

Tabel 2. Distribusi Frekuensi debris indeks sebelum

\begin{tabular}{lcccc}
\multicolumn{4}{c}{ dan sesudah mengunyah buah Apel } \\
\hline Debris Indeks & \multicolumn{2}{c}{ Sebelum } & \multicolumn{2}{c}{ Sesudah } \\
\cline { 2 - 5 } & $\begin{array}{c}\text { Frekuensi } \\
\text { (orang) }\end{array}$ & $\begin{array}{c}\text { Prosentase } \\
(\%)\end{array}$ & $\begin{array}{c}\text { Frekuensi } \\
\text { (orang) }\end{array}$ & $\begin{array}{c}\text { Prosentase } \\
(\%)\end{array}$ \\
\hline $0-0,6$ & 1 & 5 & 13 & 65 \\
$0,7-1,8$ & 12 & 60 & 7 & 35 \\
$1,9-3,0$ & 7 & 35 & 0 & 0 \\
\hline Jumlah & 20 & 100 & 20 & 100 \\
\hline
\end{tabular}

Tabel 2 menunjukkan bahwa debris indeks sebelum mengunyah buah apel 
terdapat kriteria sedang yaitu sebesar $60 \%$ atau 12 responden, sedangkan sesudah mengunyah buah apel, debris indeks kriteria baik yaitu sebesar $65 \%$ atau 13 responden.

Tabel 3. Distribusi Frekuensi debris indeks sebelum dan sesudah mengunyah buah Jambu Biji Merah

\begin{tabular}{|c|c|c|c|c|}
\hline \multirow[t]{2}{*}{ Debris Indeks } & \multicolumn{2}{|c|}{ Sebelum } & \multicolumn{2}{|c|}{ Sesudah } \\
\hline & $\begin{array}{c}\text { Frekuensi } \\
\text { (orang) }\end{array}$ & $\begin{array}{c}\text { Prosentase } \\
(\%)\end{array}$ & $\begin{array}{c}\text { Frekuensi } \\
\text { (orang) }\end{array}$ & $\begin{array}{c}\text { Prosentase } \\
(\%)\end{array}$ \\
\hline $0-0,6$ & 3 & 15 & 9 & 45 \\
\hline $0,7-1,8$ & 9 & 45 & 10 & 50 \\
\hline $1,9-3,0$ & 8 & 40 & 1 & 5 \\
\hline Jumlah & 20 & 100 & 20 & 100 \\
\hline
\end{tabular}

Tabel 3, menunjukkan bahwa debris indeks sebelum mengunyah buah jambu biji merah terbanyak berada pada kriteria sedang yaitu sebanyak 9 responden (45 \%), sedangkan sesudah mengunyah buah jambu biji merah debris indeks terbanyak berada pada kriteria sedang yaitu sebanyak 10 responden $(50 \%)$.

Tabel 4. Hasil Uji Normalitas Data Responden

\begin{tabular}{lccc}
\hline & \multicolumn{3}{c}{ Kolmogorov Smirnov } \\
\hline & Statistik & $d f$ & sig \\
\hline Debris Indeks &, 116 & 40 & .190 \\
\hline
\end{tabular}

Hasil uji statistik normalitas data didapat $p$ Value (sig.) 0,190. Karena $p$ Value (sig.) > 0,05 maka H0 diterima, sehingga dapat disimpulkan bahwa data diambil dari responden yang berdistribusi normal.

Tabel 5. Hasil Uji Homogenitas Responden

\begin{tabular}{llcccc}
\hline & & $\begin{array}{c}\text { Levene } \\
\text { Statistic }\end{array}$ & df1 & $d f 2$ & Sig. \\
\hline & Based on Mean &, 337 & 1 & 38 &, 565 \\
& Based on Median &, 274 & 1 & 38 &, 604 \\
$\begin{array}{l}\text { Debris } \\
\text { Indeks }\end{array}$ & Median and With & & & & \\
& Adjusted df &, 274 & 1 & 37,802 &, 604 \\
& Trimmed Mean &, 321 & 1 & 38 &, 574 \\
\hline
\end{tabular}

Berdasarkan hasil uji statistik homogenitas data didapat $p$ Value (sig.) 0,565 , karena $p$ Value (sig.) > 0,05, maka $\mathrm{H} 0$ ditolak sehingga dapat disimpulkan bahwa variasi pada tiap kelompok data adalah sama (homogen).

Tabel 6. Hasil uji Paired t-Test

\begin{tabular}{|c|c|c|c|c|}
\hline & Rata-Rata & $\mathrm{N}$ & Correlation & Sig. \\
\hline $\begin{array}{l}\text { Sebelum } \\
\text { Mengunyah Apel }\end{array}$ & 1,6450 & 20 & ,747 &, 000 \\
\hline $\begin{array}{l}\text { Sesudah } \\
\text { Mengunyah Apel }\end{array}$ & ,5070 & 20 & & \\
\hline $\begin{array}{l}\text { Sebelum } \\
\text { Mengunyah Jambu }\end{array}$ & 1,4800 & 20 & 845 &, 000 \\
\hline $\begin{array}{l}\text { Sesudah } \\
\text { Mengunyah Jambu }\end{array}$ & 8385 & 20 & & \\
\hline
\end{tabular}

Berdasarkan Tabel 6 uji paired t-test didapat hasil uji statistik $P=0,000$, karena $p<0,05$, maka H0 ditolak sehingga dapat disimpulkan bahwa ada pengaruh yang bermakna antara sebelum dan sesudah mengunyah buah apel dan jambu biji merah terhadap debris indeks.

Tabel 7. Hasil Uji Independent t-Test

\begin{tabular}{llcccc}
\hline & Mean & $t$ & $d f$ & $\begin{array}{c}\text { Sig. } \\
(2 \\
\text { tailed })\end{array}$ \\
\hline $\begin{array}{l}\text { Debris } \\
\text { Indeks diasumsikan }\end{array}$ & 1,1380 & 3,627 & 38 &, 001 \\
& $\begin{array}{l}\text { Varian sama } \\
\text { tidak diasumsikan }\end{array}$ &, 6415 & 3,627 & 37,618 &, 001 \\
\hline
\end{tabular}

Berdasarkan Tabel 7 didapatkan hasil statistik uji independent t-test $p$ Value (sig.2 tailed $)=0,001$, karena $p$ Value $($ Sig. 2 tailed $)$ $<0,05$ maka H0 diterima sehingga mengunyah buah apel dan jambu biji merah sama-sama efektif dalam menurunkan debris indeks.

Hasil penelitian menunjukkan bahwa sebagian besar anak usia 9-10 tahun memiliki kondisi debris indeks dengan kriteria sedang sebanyak 21 anak $(52,5 \%)$. Hal ini disebabkan karena usia tersebut, sudah bisa menjaga kebersihan diri sendiri. Siswa yang termasuk kriteria buruk sebanyak 15 siswa dan sebagian besar pada anak usia 8 tahun, hal ini disebabkan anak-anak pada umumnya belum dapat merawat giginya sendiri sehingga perlu diajari cara menyikat gigi yang benar, waktu menyikat gigi yang tepat dan di ajak makan buah-buahan yang mengandung serat dan memiliki daya membersihkan gigi sendiri, sehingga dapat menjaga kebersihan gigi dan mulut anak- 
anak dan dapat mencegah terjadinya karies gigi (Ariningrum, 2000).

Hasil uji paired t-test menunjukkan bahwa debris indeks anak usia 8-10 tahun di SD Muhammadiyah Sangonan II mengalami penurunan setelah mengunyah buah apel dan jambu biji merah. Penurunan ini terjadi karena buah apel dan jambu biji merah merupakan makanan berserat dan padat yang mempunyai kemampuan untuk dapat mendorong sekresi air ludah terhadap rongga mulut sehingga terjadi self cleansing di dalam mulut (Milati, 2009). Self Cleansing adalah pembersihan secara alami pada gigi terhadap sisa-sisa makanan yang tertinggal di dalam mulut (Grandfa, 2007).

Pencegahan primer pada anak yang beresiko karies tinggi bahwa memperbanyak makan sayuran dan buah-buahan berserat dan berair akan bersifat membersihkan dan merangsang sekresi saliva sehingga karies gigi dapat dicegah (Langitan, 2010). Buahbuahan berserat yang baik dikonsumsi sebagai pengganti makanan manis sekaligus sebagai self cleansing pada gigi misalnya apel, jambu, nanas dan bengkuang (Ariningrum, 2000).

Hasil uji independent t-test menunjukkan bahwa mengunyah buah apel dan jambu biji merah sama-sama efektif dalam menurunkan debris indeks. Hal ini disebabkan karena kandungan air dan serat buah apel dan jambu biji merah yang hampir sama serta tekstur daging buah yang padat, kasar dan keras. Kandungan air dalam apel sebesar 80 gr, kandungan serat 5 gram, sedangkan kandungan air dalam jambu biji merah sebesar 86,10 gram, kandungan serat 5,4 gram. Selain itu cara mengunyah dan lama mengunyah yang dikendalikan dapat mempengaruhi penurunan debris indeks, karena mengunyah akan meningkatkan jumlah air ludah dan pengunyahan dipengaruhi oleh kekerasan dari jenis makanan (Meishi, 2011).

\section{KESIMPULAN}

Hasil dari penelitian yang telah dilakukan dapat diambil kesimpulan bahwa :

1. Mengunyah buah apel berpengaruh terhadap debris indeks

2. Mengunyah buah jambu biji merah berpengaruh terhadap debris indeks

3. Mengunyah buah apel lebih efektif dari pada mengunyah jambu biji merah dalam menurunkan debris indeks.

\section{DAFTAR PUSTAKA}

Angela A, 2005. Pencegahan Primer pada Anak Yang Beresiko Karies Tinggi. Dental journal, Vol. 38 No. 3 Hal 130-134.

Ariningrum, R. 2000. Beberapa cara Menjaga Kebersihan Gigi dan Mulut. Cermin Dunia Kedokteran No.126/2000.

Cahyati, W.H, 2013, Konsumsi Pepaya dalam Menurunkan Debris Index. Jurnal Kesehatan Masyarakat, Vol. 8 No. 2.

Dalimunthe, S,H. 2008. Periodontia. Medan : USU Press

Gopdianto, R., Rattu A.J.M., dan Mariati, N.N, 2015, Status Kebersihan Mulut dan Perilaku Menyikat Gigi Anak SD Negeri I Malalayang. Jurnal $e$ - GIGI.

Grandfa, 2007, Jangan Remehkan Kesehatan Gigi dan Mulut, http://id.shyoong.com/medicine-andhealth/1648986.

Hidayanti, L. 2007, Peran Buah dan Sayur Dalam Menurunkan Keparahan Karies Gigi pada Anak. Fakultas Kesehatan Masyarakat. Universitas Siliwangi, Tasikmalaya 
Langitan, T, 2010, Peran Saliva dalam Pencegahan Karies. Studi Pustaka (published). Manado Fakultas Kedokteran Universitas Sam Ratulangi.

Lestari, S. dan Malahayati, C, 2004, Pengaruh Makan Apel Dalam Pembentukan Plak Pada Anak-anak Panti Asuhan Al-Khairiyah. Jakarta : Jurnal PDGI 54,1

Mangku, 2009, Jorok 77 Persen Orang Indonesia Malas sikat Gigi http://www.suarakaryaonline/news.html.id=180439.

Meishi, P.R.L, 2011, Hubungan Tingkat Konsumsi Makanan Kariogenik dengan Karies Gigi pada Anak Sekolah dasar Swasta Muhammadiyah 08 Medan. Skripsi. FKM USU.

Milati, N, 2009, Jangan Remehkan Kesehatan Gigi dan Mulut Anak-anak http://lovemydentist.multiply.com/jou rnal.

Putri, M.H., Herijulianti, E dan Nurjannah, N., 2012, Ilmu Pencegahan Penyakit Jaringan Keras dan pendukung Gigi, Jakarta : EGC 